\title{
Experimental Research on the Relationship between Temperature and Humidity of Glass-greenhouse in Summer
}

\author{
Jian $\mathrm{Hu}^{1, \mathrm{a}}$ Weiqing $\mathrm{Li}^{2, \mathrm{~b}}$ \\ ${ }^{1}$ College of Water Conservancy and Hydropower Engineering, \\ Sichuan Agricultural University,Yaan 620514 ,China \\ ${ }^{2}$ College of Engineering and Technology, Southwest University, \\ Chongqing 400716, China \\ ahjsicau@126.com, b348268569@qq.com
}

\begin{abstract}
Keywords: Cooling system, Temperature, humidity, the variation relationship between the temperature and humidity.

Abstract. This paper is devoted to describe the variation trend of temperature and humidity in the glasshouse in summer during the working of the four main cooling systems, i.e. natural ventilation system, mechanical ventilation system, wet curtain cooling system.Then, set up the quantitative relationship between the temperature and humidity by regression analysis method, as well as fit the variation relationship between the two factors by the use of linear function, logarithmic function, binomial distribution function, power function and exponential function. The result shows that the best fitting degree among the three cooling system is all by binomial function operational method, and the correlation coefficient of the binomial function is the highest one among the four, which reach: 0.9847 , 0.9725 and 0.9813 respectively.
\end{abstract}

\section{Introduction}

During the summer cooling process, the two variables, temperature and humidity, in the greenhouse, are in the same variation condition. The two are not without contact, but in interaction and mutual checks. The relationships of variables can be divided into two types, namely deterministic relationship and correlation. Deterministic relationship means that one variable can be certain by another determined variable in a certain function relationship. While, in correlation, though there are relationships among some variables, this relationship can't be expressed by a certain function. In order to deeply understand the essence of the matter, quantitative relations among these variable are frequently needed to be explored. Regression analysis is such a method that looks for the mathematical relationship of this kind of variables and conducts statistical inference, which is also an important part of mathematical statistics. Its task is used to research the correlation among different variables, and to set up empirical formula among the variables, so as to reach the purpose of prediction and control. The specific way is: to make scatter diagram first, and compare the present shape of the regression analysis with the common known function graph, then configure out an appropriate curve. Meanwhile, the function can be transformed into linear function through the appropriate variables, and then transform nonlinear regression model into linear regression model.

\section{Experiment Conditions and Test Scheme}

\section{Experiment Conditions}

This experiment proceeded in water-saving irrigation efficiency demonstration laboratory of College of Engineering and Technology, Southwest University. The laboratory is a type of four straight across venlo, which is a large high-grade glass greenhouse with one cross and three ridges. It is divided into four parts, including vegetables area, flowers area, fruits area and nurseries garden, which with a central control room in the front of the flowers area. The greenhouse is equipped with natural ventilation system, mechanical ventilation system, wet curtain cooling system, internal and external 
cooling system and other relevant control equipments. 16 numbers of thermocouple sensors and thermal performance test systems of TRM-2 type of solar energy water heater are decorated in the greenhouse (Jinzhou sunshine technology development co., LTD. Development), which are used for temperature data automatic recording. The setting time is every 30 minutes once sampling. Three wet and dry bulb thermometers are also placed in the greenhouse, one is placed outdoors, and the other two are placed indoors, which are respectively used to measure the dry-bulb temperature, the wet-bulb temperature and the relative humidity between outdoors and indoors.

\section{Test Arrangement}

This test is conducted in the flowers area, the second area of the greenhouse, which shows in figure 1. Greenhouse is divided into two symmetrical working areas by the corridor. And six observation points are set up on the horizontal plane area of the right side, among which a temperature sensor is placed in the third position with a distance of $20 \mathrm{~cm}$ underground. This temperature sensor is used to measure the geothermal change rule during the whole experimental process. The seventh observation point is placed outdoors. In addition, there are another three wet and dry bulb thermometers, one is placed outer greenhouse and the other two placed indoors.

Figure 2 is the temperature vertical distribution map of each point. Three planes are set up in vertical direction, and the third plane is $500 \mathrm{~mm}$ distance from ground, and the first plane is $500 \mathrm{~mm}$ distance from the gutter. They are used for measuring the variation of temperature in vertical direction. All the temperature data are the automatic record of thermal performance test system of TRM - 2 type solar energy water heater by every 30 minutes. The relative humidity is recorded by worker every 30 minutes.

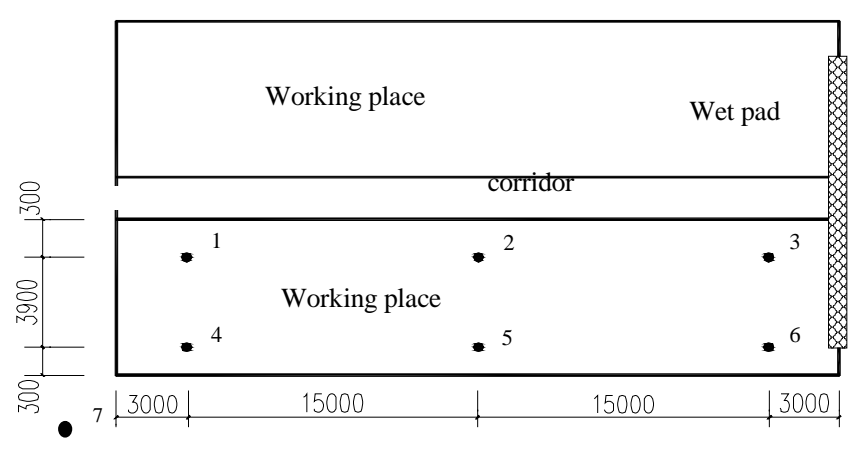

Figure1. The horizontal distribution of every measuring point in flowers area

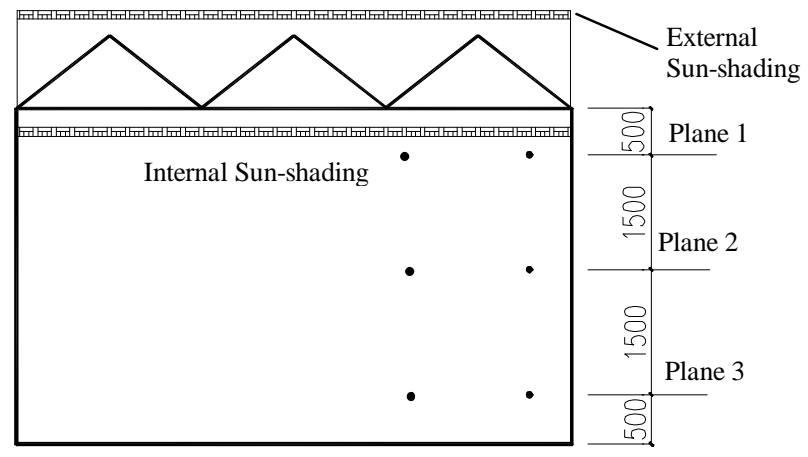

Figure2. The vertical distribution of every measuring point in flowers area

\section{Test result and analysis}

\section{The Natural Ventilation System}

The natural ventilation cooling system is opened at nine o 'clock in the morning, and the contrast diagram of the temperature and humidity indoors variations are shown in figure 3. After natural ventilating, the temperature indoors appears small amplitude decline and then begins to rise, and the rising speed is close to that at noon time. The humidity indoors appears a contrary variation trend, which shows decline when temperature increases. Besides, the two variation curves are basically symmetric. Making temperature as abscissa, humidity as ordinate in the same coordinate system, it can come into been a scatter diagram of temperature and humidity when the data of these two factors at a given time are labeled on the coordinate system. As figure 4 shows, temperature and humidity is obviously relevant.

This paper adopts linear function $(y=a x+b)$, logarithmic function $(y=a \ln x+b)$, binomial function $\left(\mathrm{y}=\mathrm{a} x^{2}+b x+c\right)$, power function $\left(y=a x^{b}\right)$ and the index function $(y=a \exp (b x))$ to fit the splattering in figure 4 , to get the fitting correlations of the five functions above respectively, as i shown in table 1 ( $\mathrm{x}$ 


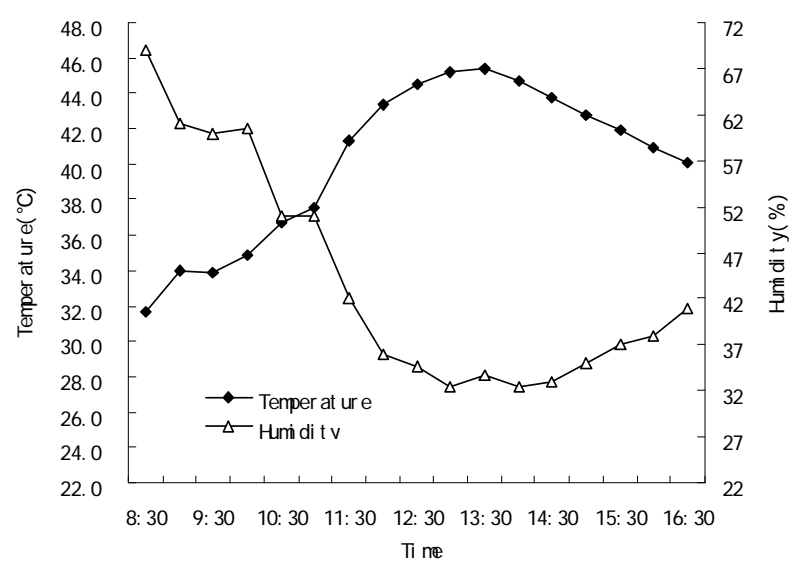

Figure 3. The temperature and humidity variation diagram in greenhouse with natural ventilation cooling svstem

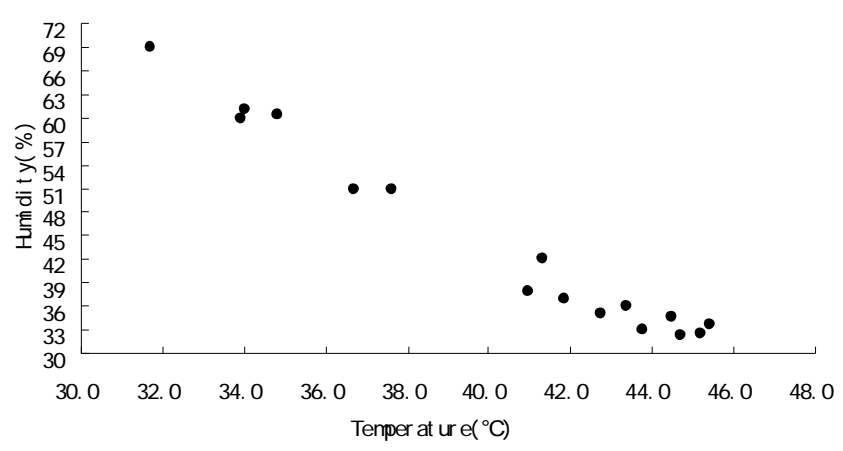

Figure 4. The temperature and humidity relation diagram in greenhouse with natural ventilation cooling system

correlation coefficients of the five functions reach 0.97 , and the binomial function fits the highest degree, reaching 0.9847; in addition, the logarithmic function has a good fitting degree, and its correlation coefficient is 0.9789 .

Table 1 Fitting relation of temperature and humidity via natural ventilation

\begin{tabular}{lll}
\hline Fitting function & Fitting relation & Correlation coefficient \\
\hline Linear function & $\mathrm{y}=-2.6616 \mathrm{x}+151.06$ & 0.9713 \\
logarithmic function & $\mathrm{y}=-103.41 \mathrm{Ln}(\mathrm{x})+425.37$ & 0.9789 \\
Quadratic function & $\mathrm{y}=0.0968 \mathrm{x}^{2}-10.211 \mathrm{x}+296.25$ & 0.9847 \\
Power function & $\mathrm{y}=148257 \mathrm{x}^{-2.2119}$ & 0.9784 \\
Exponential function & $\mathrm{y}=422.81 \mathrm{e}^{-0.0571 \mathrm{x}}$ & 0.9773 \\
\hline
\end{tabular}

\section{Mechanical Ventilation System}

From 9:00 to 11:00 am, the rate of temperature increases relatively slowly, and relative humidity changes little during the same time. After 11:00 am, temperature increases significantly faster than before, meanwhile humidity also declines obviously, and at 12:30 pm the temperature reaches its maximum and humidity reaches its minimum. After that, both show a decline trend. Only when it reaches 14:30 pm, temperature and humidity reach their maximum and minimum respectively, which is shown in figure 5. Figure 6 shows that the temperature and humidity are obviously related when they are represented in the same coordinate system. By using linear function, logarithmic function, binomial function, power function and exponential function to fit each scatter, fitting correlations of five kinds of functions above and the fitting correlation coefficient are gotten, as shown in table 2. Through comparing the five correlation coefficients in table 2, it is easy to see that binomial function fitting degree is the best, which reaches 0.9725 . The other four functions fitting correlation coefficients are also not low, all of which are more than 0.96 .

\section{Wet Curtain Cooling System}

The wet curtain cooling system is opened at nine o 'clock in the morning, and the contrast diagram of the temperature and humidity indoors variations are shown in figure 7 . From the temperature variation curve, it is obvious that the temperature plummets, and the degree of plummeting reaches $11.2 \%$. After that, the temperature gradually begins to rise, early warming faster; next to afternoon, the speed slows down until it reaches the maximum. The variation tendency of the humidity is on the 
contrary, it increases in a straight line after turning on the wet curtain cooling system, and the degree of increasing is up to $20.8 \%$, and then with the rise of temperature, it decreases

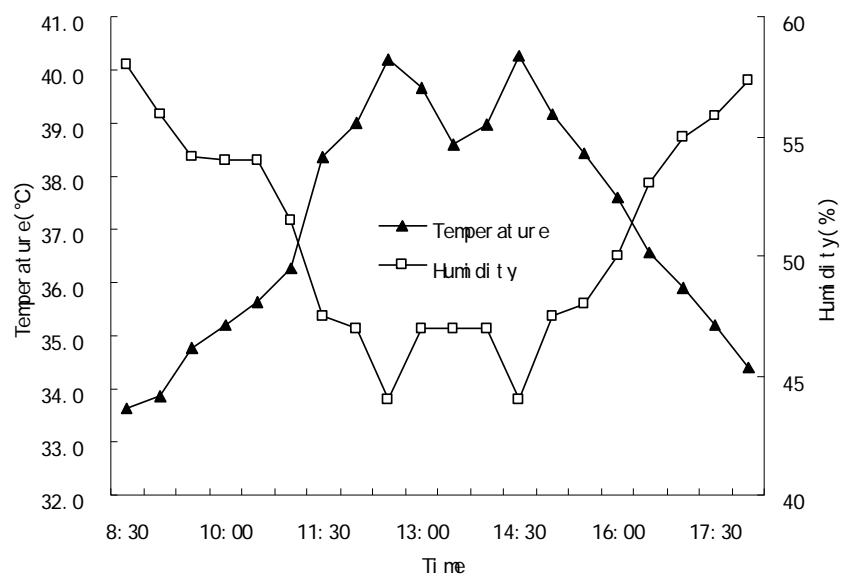

Figure 5 The temperature and humidity variation diagram in greenhouse with mechanical ventilation system

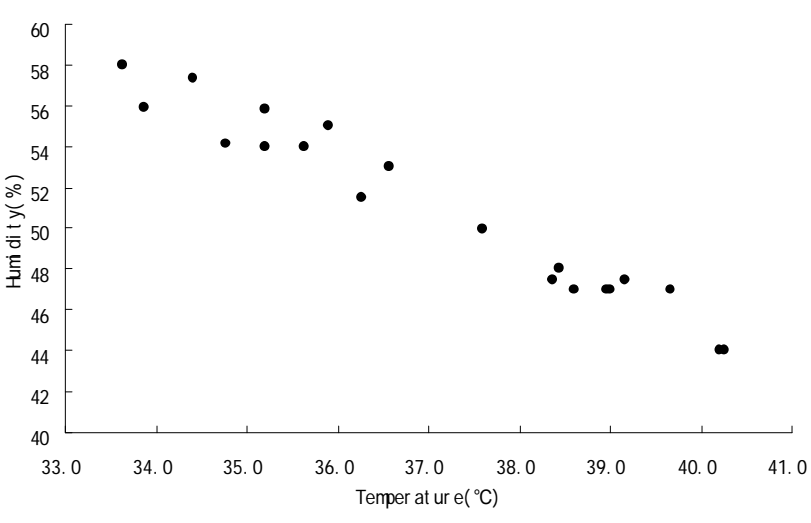

Figure 6 The temperature and humidity relation diagram in greenhouse with mechanical ventilation system

Table 2 Fitting relation of temperature and humidity via mechanical

\begin{tabular}{lll}
\hline Fitting function & Fitting relation & $\begin{array}{l}\text { Correlation } \\
\text { coefficient }\end{array}$ \\
\hline Linear function & $\mathrm{y}=-2.0232 \mathrm{x}+125.9$ & 0.9704 \\
Log function & $\mathrm{y}=-74.618 \operatorname{Ln}(\mathrm{x})+320.35$ & 0.9678 \\
Quadratic function & $\mathrm{y}=-0.0575 \mathrm{x}^{2}+2.2293 \mathrm{x}+47.475$ & 0.9725 \\
Power function & $\mathrm{y}=10278 \mathrm{x}^{-1.4709}$ & 0.9642 \\
Exponential function & $\mathrm{y}=222.64 \mathrm{e}^{-0.0399 \mathrm{x}}$ & 0.9681 \\
\hline
\end{tabular}

gradually. Representing the temperature and humidity data in the same coordinate system, it is obviously that they are related, as shown in figure 8. By using linear function, logarithmic function, binomial function, power function and exponential function to fit each scatter, fitting correlations of five kinds of functions above and the fitting correlation coefficient are gotten, as shown in table 3.

Through comparing the five correlation coefficients in table 3 , it is easy to see that binomial function fitting degree is the best, which reaches 0.9813 . The other four functions fitting correlation coefficients are also not low, all of which are more than 0.97 .

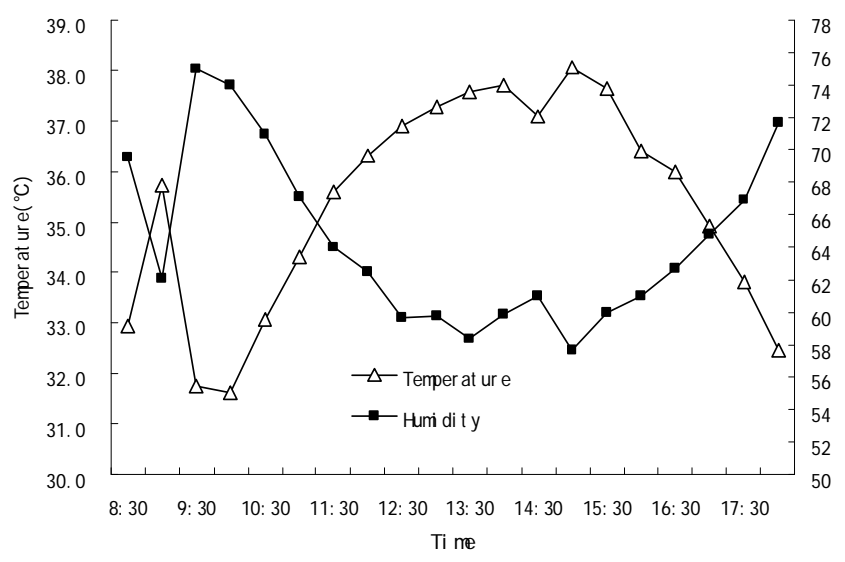

Figure 7 The temperature and humidity variation diagram in greenhouse with wet curtain cooling system

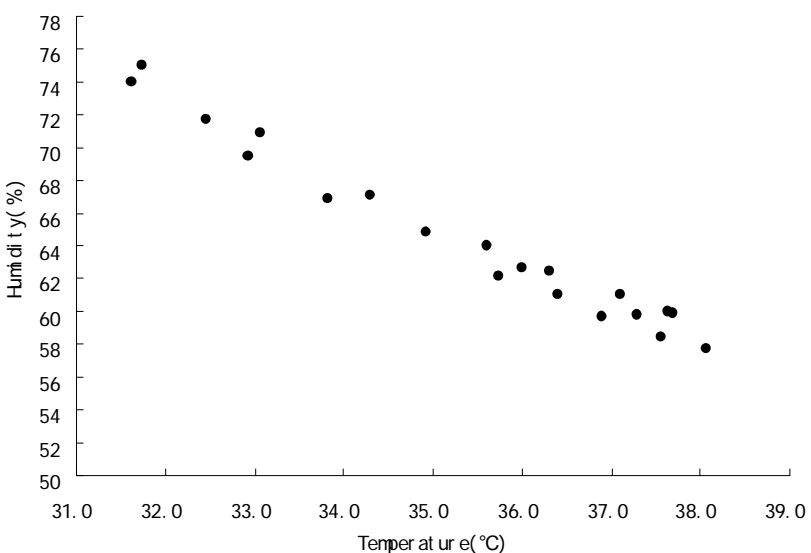

Figure 8 The temperature and humidity relation diagram in greenhouse with wet curtain cooling system 
Table 3 Fitting relation of temperature and humidity via wet curtain cooling system

\begin{tabular}{lll}
\hline Fitting function & Fitting relation & Correlation coefficient \\
\hline Linear function & $\mathrm{y}=-2.2035 \mathrm{x}+138.41$ & 0.9454 \\
Log function & $\mathrm{y}=-72.985 \mathrm{Ln}(\mathrm{x})+320.86$ & 0.9505 \\
Quadratic function & $\mathrm{y}=0.4441 \mathrm{x}^{2}-31.561 \mathrm{x}+623.2$ & 0.9806 \\
Power function & $\mathrm{y}=3142.8 \mathrm{x}^{-1.1065}$ & 0.9550 \\
$\begin{array}{l}\text { Exponential } \\
\text { function }\end{array}$ & $\mathrm{y}=197.77 \mathrm{e}^{-0.0334 \mathrm{x}}$ & 0.9503 \\
\hline
\end{tabular}

\section{Conclusions and Discussions}

(1)During the cooling process of natural ventilation system, mechanical ventilation system, wet curtain cooling system, these three cooling systems, it is obvious about the correlation between temperature and humidity.

(2) In the cooling process of these three kinds of cooling systems, the temperature and humidity indors variation trends show on the contrary. And the variation curves of the two basically keep a symmetrical distribution.

(3) By using linear function, logarithmic function, binomial function, power function and exponential function these five functions to fit the relativity between temperature and humidity, it shows that the fitting correlation coefficient of quadratic function among the five above is the highest, and its fitting degree is also the best one.

(4) This experiment is proceeded in Beibei District of Chongqing Municipality in August, and the experimental data are affected by geographic location, greenhouse structure, environment control equipment, weather conditions, and many other factors. So the Correlation function relationship of the temperature and humidity resulted from the experimental data in this paper is limited, which need a further research.

\section{References}

[1] Ma Chengwei,Miao Xiangwen. Agricultural biological environment engineering[M]. Beijing:China Agriculture Press , 2005 , 90 143

[2] Wang Jiqing,Zhang Bailiang.Application of some cooling measures for greenhouse cooling in summer[J]. Transactions of the CSAE, 2006,22 ( 9 ) : $257 \sim 260$

[3] Hu Jian.Cooling effects research on glass-greenhouse of Chongqing in summer[D]. Master's degree thesis of southwest university,2008

[4] Qiao Ke,Pen Yi,Liu Li. Observation and analysis of thermal environmental conditions of semi-enclosed livestock houses in summer in Chongqing, Journal of Southwest Agricultural University(Natural Science) $2006,28(2): 345 \sim 348$

[5] Arbel A , Yekutieli O , Barak M.Performance of a Fog System for Cooling Greenhouses [J],J Agric Engng Res,1999, ( 72 ) :129 136

[6]Hayashi M , Sughara T.Temperature and humidity environments inside a naturally ventilated greenhouse with the evaporative fog cooling system[J] .Environ Control Biol , 1998,36 ( 2 ) : $97 \sim 104$ 